\title{
Intestinal lymphangiectasia associated with angiofollicular lymph node hyperplasia (Castleman's disease)
}

\author{
S F Moss, D M Thomas, C Mulnier, I G McGill, H J F Hodgson
}

Departments of Medicine and Histopathology, Royal Postgraduate Medical School, Hammersmith Hospital, London

S F Moss

D M Thomas

C Mulnier

H J F Hodgson

Department of Medicine, Torbay Hospital, Devon I G McGill

Correspondence to:

Dr S F Moss, Department of Gastroenterology, Royal

Postgraduate Medical School Hammersmith Hospital Du Cane Road, London W120HS.

Accepted for publication 2 April 1991

\begin{abstract}
A patient presenting with predominantly gastrointestinal symptoms and a history of myocardial infarction was found to have ascites, hepatosplenomegaly, para-aortic lymphadenopathy, thrombocytosis, and a paraproteinaemia. A jejunal biopsy specimen showed lymphangiectasia and histology of the spleen and lymph nodes showed angiofollicular hyperplasia or Castleman's disease of the hyaline vascular type. This association has not previously been described and, moreover, systemic symptoms are unusual in this variant of Castleman's disease.
\end{abstract}

Intestinal lymphangiectasia is an uncommon entity characterised by dilated lymphatics within the gut. It may be primary or secondary to lymphatic obstruction in a number of inflammatory or neoplastic conditions ${ }^{1}$ or in right heart failure, where the lymphatic return from the intestine may be compromised. It may present with the consequences of protein losing enteropathy and is occasionally associated with immunodeficiency caused by the loss of $T$ cells into the intestinal lumen. ${ }^{2}$

Castleman's disease, or angiofollicular lymph node hyperplasia, is a rare lymphoproliferative disorder of unknown aetiology. It usually occurs as a solitary, symptomless, mediastinal mass characterised histologically by lymphoid follicle like structures with prominent proliferation of blood vessels. ${ }^{3}$ Two subtypes are described, probably representing the extremes of a spectrum of appearances. ${ }^{+}$The hyaline vascular type is by far the more common, while the plasma cell variant is more likely to be associated with systemic symptoms, particularly when the condition is multicentric rather than solitary.

\section{Case history}

A 49 year old female teacher presented with a four year history of malaise and one year of nausea, abdominal swelling, and the passage of loose watery stools three times daily. Over this time she had lost $10 \mathrm{~kg}$ in weight. She also complained of numbness in both feet and of the symptoms of Raynaud's phenomenon affecting the left arm. Breathlessness prevented her from climbing more than two flights of stairs. Two years previously she had suffered an uncomplicated transmural inferior myocardial infarction. At this time she had a mild thrombocytosis with a platelet count of $600 \times 10^{9} / 1$ but no other risk factors for ischaemic heart disease. She was taking aspirin (75 mg daily) and bumetanide with potassium.

On physical examination there were no signs

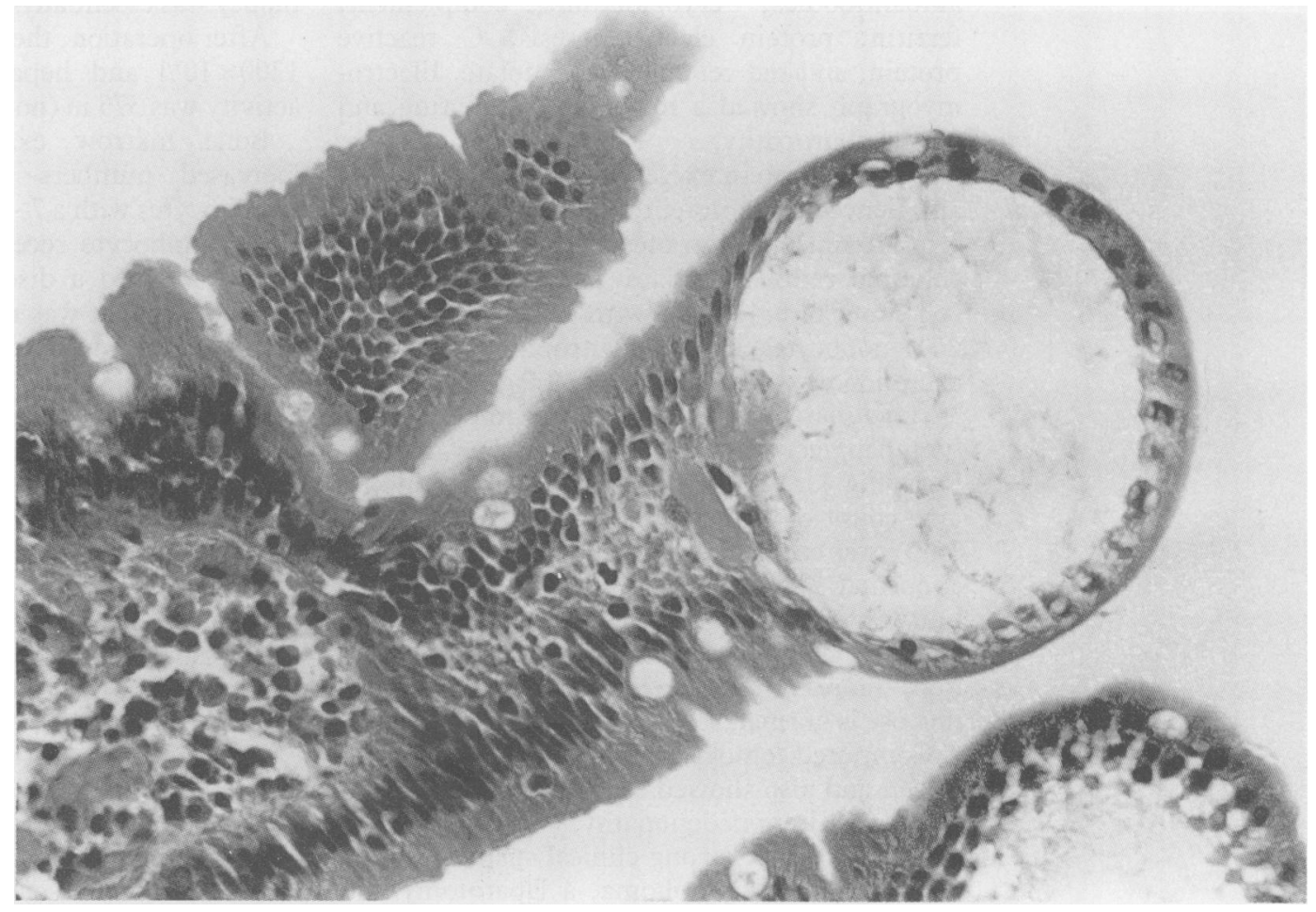




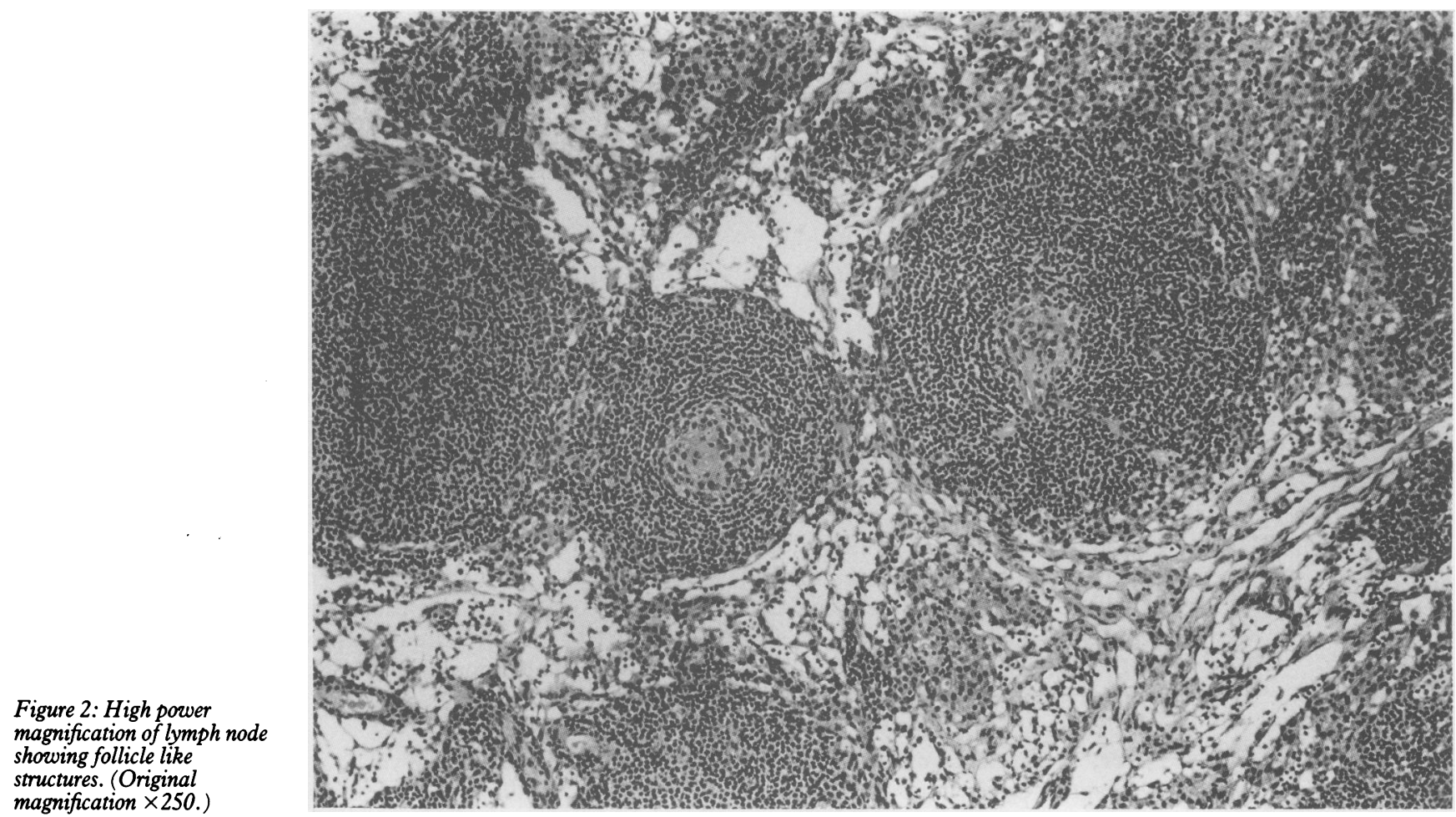

of heart failure and no lymphadenopathy. There were ascites, moderate splenomegaly, and a sensory peripheral neuropathy in a glove and stocking distribution.

All haematological indices, including a bone marrow trephine, were normal except for a raised platelet count of $600 \times 10^{9} / 1$. The alkaline phosphatase value was high at $176 \mathrm{iu} / 1$ but she had normal transaminase activities and total globulin concentrations. An IgA lambda paraprotein was detected in the serum by immunofixation, at a concentration of less than $1 \mathrm{~g} / \mathrm{l}$. The following investigations were either negative or within the normal range: urea and electrolytes, autoantibodies, cryoglobulin, complement, ferritin, protein electrophoresis, $\mathrm{C}$ reactive protein, and red cell and serum folate. Electromyograph showed a mixed demyelinating and axonal neuropathy.

Urinary protein excretion was $0.4 \mathrm{~g} / 24$ hours and Bence-Jones protein was not detected.

Abdominal paracentesis showed a straw coloured cellular exudate (protein $50 \mathrm{~g} / \mathrm{l}$ and a cell count of $5 \cdot 4 \times 10^{9} / 1$, with $68 \%$ lymphocytes, $26 \%$ monocytes, and $4 \%$ neutrophils). Faecal fat excretion was slightly raised at $5.9 \mathrm{~g} / 24$ hours.

A jejunal mucosal biopsy specimen showed lymphangiectasia with a normal villous architecture (Fig 1). A reduced intraepithelial lymphocyte count of 8 per 100 epithelial cells (normal 18.0 ), was consistent with this diagnosis ${ }^{5}$ and the abnormal mucosa further excluded the possibility that the specimen had been taken from a localised lymphangiectatic cyst. In this condition, more often seen in older patients, the mucosa is normal. ${ }^{6}$

Computed tomogram confirmed the enlarged spleen and also showed mild hepatomegaly and para-aortic lymphadenopathy.

Because of the strong clinical suspicion of an intra-abdominal lymphoma, a laparotomy and splenectomy were performed together with a liver biopsy.

Histology of the lymph nodes showed partial replacement of the normal architecture by structures comprising concentric rings of small lymphocytes surrounding small follicle centres containing hyalinised vessels that were occasionally seen to enter the follicle radially (Fig 2). The interfollicular areas showed proliferating blood vessels.

The spleen showed expansion of the white pulp with similar follicle like structures and the overall appearances were those of multicentric, hyaline vascular Castleman's disease. The liver biopsy was essentially normal.

After operation, the platelet count doubled to $1200 \times 10^{9} / 1$ and hepatic alkaline phosphatase activity was 375 iu (normal $<130$ ).

Bone marrow examination now showed increased numbers of megakaryocytes and lymphocytes with a 7-10\% eosinophilia.

$T$ lymphocyte receptor gene rearrangement studies showed a discrete $\mathrm{T}$ cell clone in the ascitic fluid that was not seen in the peripheral blood. There was no evidence of an abnormal B cell clone.

Eight months later, the peripheral blood showed a persistent thrombocythaemia and also a raised haematocrit $(0.5)$ and red cell volume (when corrected for plasma volume) consistent with polycythaemia. This was considered evidence of the development of a myeloproliferative process and in view of this and of the slowly progressive neurological symptoms, treatment with cyclophosphamide and prednisolone was begun.

\section{Discussion}

Our patient exhibited a number of systemic features usually associated with the plasma cell 
variant of Castleman's disease, including weight loss, fever, thrombocythaemia, ${ }^{7}$ paraproteinaemia, ${ }^{7}$ peripheral neuropathy, ${ }^{78}$ and myocardial infarction.9 Other reported features include amyloidosis ${ }^{10}$ and anaemia (which may be due to circulating antierythrocyte antibody). ${ }^{11}$

The pathogenesis of Castleman's disease is unknown but a number of lines of evidence point to it being an immunoproliferative condition. Monoclonal plasma cell populations have been shown in some cases of the plasma cell type ${ }^{1213}$ and $T$ cell gene rearrangements have been associated with Epstein-Barr virus incorporation. ${ }^{13}$ These abnormalities seem confined to the multicentric form of the disease. Moreover, production of the cytokine interleukin 6 by Castleman's nodes has been shown both in vitro ${ }^{14}$ and in vivo. ${ }^{15}$ Our patient had $\mathrm{T}$ cell gene rearrangement in the ascitic fluid though not in the peripheral blood.

One study reports a high rate of progression of the hyaline vascular form to angiomatous neoplasms ${ }^{16}$ but as the morphology of Castleman's nodes may resemble that seen in nodes draining malignant tumours, in autoimmune conditions, in HIV infection, and in Kaposi's sarcoma ${ }^{17}$ this association remains unproved.

Castleman's disease may present to the gastroenterologist in a number of ways - as hepatosplenomegaly, abdominal lymphadenopathy, or as a mass in the stomach or pancreas. ${ }^{18} 19$ However, intestinal lymphangiectasia secondary to this condition has not previously been described and in this patient is probably a result of the paraaortic and mesenteric lymphadenopathy of multicentric Castleman's disease.

1 Strober W. In: Bouchier IAD, Allan RN, Hodgson HJF, Keighley MRB, eds. Textbook of gastroenterology. London: Baillière Tindall, 1984: 598-615.
2 Strober W, Wochner RD, Carbone PP, Waldmann TA. Intestinal lymphangiectasia: a protein losing enteropathy
with hypogammaglobulinaemia, lymphocytopaenia and with hypogammaglobulinaemia, lymphocytopaenia and
impaired homograft rejection. $\mathcal{F}$ Clin Invest 1967; 46: 1643impair.

3 Castleman B, Iverson L, Menendez VP. Localised mediastinal lymph node hyperplasia resembling thymoma. Cancer 1956 9: 822-30.

4 Keller AR, Hochholzer L, Castleman B. Hyaline vascular and plasma cell types of giant lymph node hyperplasia of mediastinum and other locations. Cancer 1972; 29: 670-83.

5 Myszor MF, Davidson A, Hodgson HJF. The local mucosal immune system in intestinal lymphangiectasia. $\mathcal{f} \mathrm{Clin} \mathrm{Lab}$ Immunol 1988; 26: 1-3.

6 Steinar A, Gundersen R. Submucous lymphatic cysts of the small intestine. Acta Pathol Microbiol Scand $[B]$ 1983; 91: $191-4$.

7 Hineman VL, Phyliky RL, Banks PM. Angiofollicular lymph node hyperplasia and peripheral neuropathy: association node hyperplasia and peripheral neuropathy: association
with monoclonal gammopathy. Mayo Clin Proc 1982; 57: with mon-82.

8 Donaghy M, Hall PA, Gawler J, et al. Peripheral neuropathy associated with Castleman's disease. F Neurol Sci 1989; 89. 253-67.

9 Case records of the Massachusetts General Hospital. N Englf Med 1987; 316: 606-18.

10 West KP, Morgan DA, Lauder I. Angiofollicular lymph node hyperplasia with amyloidosis. Postgrad Med f 1989; 65: 108-11.

11 Steinberg JL, Huang PL, Ljubich P, Lee-Huang S. Antierythropoietin antibody in hyperviscosity syndrome associated with giant lymph node hyperplasia (Castleman's ated with giant lymph node hyperplasi
disease). Br $\mathscr{f}$ Haematol 1990; 74: 543-44.

12 Hall PA, Donaghy M, Cotter FE, Stansfeld AG, Levison DA. An immunohistochemical and genotypic study of the plasma cell form of Castleman's disease. Histopathology 1989; 14 $333-46$

13 Hanson CA, Frizzera G, Patton DF, et al. Clonal rearrangement for immunoglobulin $\mathrm{T}$ cell receptor genes in systemic Castleman's disease: association with Epstein-Barr virus. Am ₹ Pathol 1988; 131: 84-91.

14 Yabuhara A, Yanagisawa M, Murata T, et al. Giant lymph node hyperplasia (Castleman's disease) with spontaneous production of high levels of $B$ cell differentiation factor activity. Cancer 1989; 63: 260-5.

15 Yoshizaki K, Matsuda T, Nishimoto N, et al. Pathogenic significance of interleukin-6 (IL-6/BSF-2) in Castleman's significance of interleukin-6 (II
disease. Blood 1989; 74: 1360-7.

16 Gerald W, Kostianovsky M, Rosai J. Development of vascular neoplasia in Castleman's disease: report of 7 cases. Am f Surg Pathol 1990; 14: 603-14.

17 Frizzera G. Castleman's disease: more questions than answers. Hum Pathol 1985; 16: 202-5.

18 Yebra M, Vargas JA, Menendez VP, et al. Gastric Castleman's disease with a lupus-like circulating anticoagulant. $A m \mathcal{F}$ Gastroenterol 1989; 84: 566-70.

19 LeVan TA, Clifford S, Staren ED. Castleman's tumour masquerading as a pancreatic neoplasm. Surgery 1989; 106: 